INTERNATIONAL DESIGN CONFERENCE - DESIGN 2018

https://doi.org/10.21278/idc.2018.0430

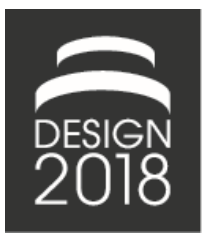

\title{
AESTHETIC INTERACTION CONSISTENCY: EXPLORING THE FOUNDATION FOR STATIC AND DYNAMIC AESTHETICS
}

\author{
I. Gonzalez, E. Val, D. Justel, I. Iriarte and G. Lasa
}

\begin{abstract}
Aesthetics is a powerful means for creating consistency across a product range. During the design process consistency is subject to risk. The existing tools do not integrate static as well as dynamic approaches. This paper explores how to integrate and combine both. The framework considers that, firstly, the users perceive the product thought all their senses (product presentation). Based on the perceptions, users will interact through gestures or movements (user action). These action will create a product reaction (product reaction). Finally, the frame has been applied in an experiment.
\end{abstract}

Keywords: aesthetics, design evaluation, product design, consistency, aesthetic interaction

\section{Introduction}

In design management literature, industrial design is often discussed from the viewpoint of product identity and branding (Warell, 2001). Design is a powerful means of strengthening the brand recognition (identification) and of creating coherence across different market and product categories (consistency) (Karjalainen, 2004). To do so, companies rely on aesthetic consistency.

Cambridge dictionary defines consistency as "being the same", or "the quality of always behaving or performing in a similar way, or of always happening in a similar way". Companies designing and producing a range of products have to consider common design features to keep aesthetic consistency (Warell, 2001; Karjalainen, 2007).

Traditional approaches focused on static visual features to define the appearance of products, such as colour, form and materials (Schwarzfischer, 2011). However, recent researches are claiming the relevance of dynamic features representing the interactivity of products. Thus, features like gestures and movements are also considered, as a means to describe them (Lenz et al., 2014; Lenz et al., 2017). In the near future, aesthetic consistency will combine both, static as well as dynamic features in order to strengthening the brand.

\section{Context}

During the design process consistency is subject to risk. The process of coding ideas and brand values into products is a complex practice (Gonzalez et al., 2016, 2017). Therefore, there are theories that help designers to understand and develop it (Bloch, 1995; Cupchik, 1999; Norman, 2004; Crilly et al., 2004, 2009; Karjalainen, 2007; Hestard, 2013; Newbery and Farnham, 2013). For instance, Crilly et al. (2004, 2009) studied how the visual form of product was interpreted by consumers and they characterized the factors that influenced those interpretations. They also looked into the intentions of the design, the factors that influenced those intentions and the influence of those intentions on the product. However, product form and consumer response are determined by an ample quantity of factors. These factors 
interact with one another in a complex and unpredictable way. This is why Neumeier (2003) claims that most of the time, there is a gap between what the company wants to communicate to the user and what the user perceives. This is referred to as Brand Gap. The Brand Gap concept represents the inconsistencies between what the brand wants to achieve and what the consumer experiences and it is partly linked to aesthetic inconsistencies (Gonzalez et al., 2016) (Figure 1).

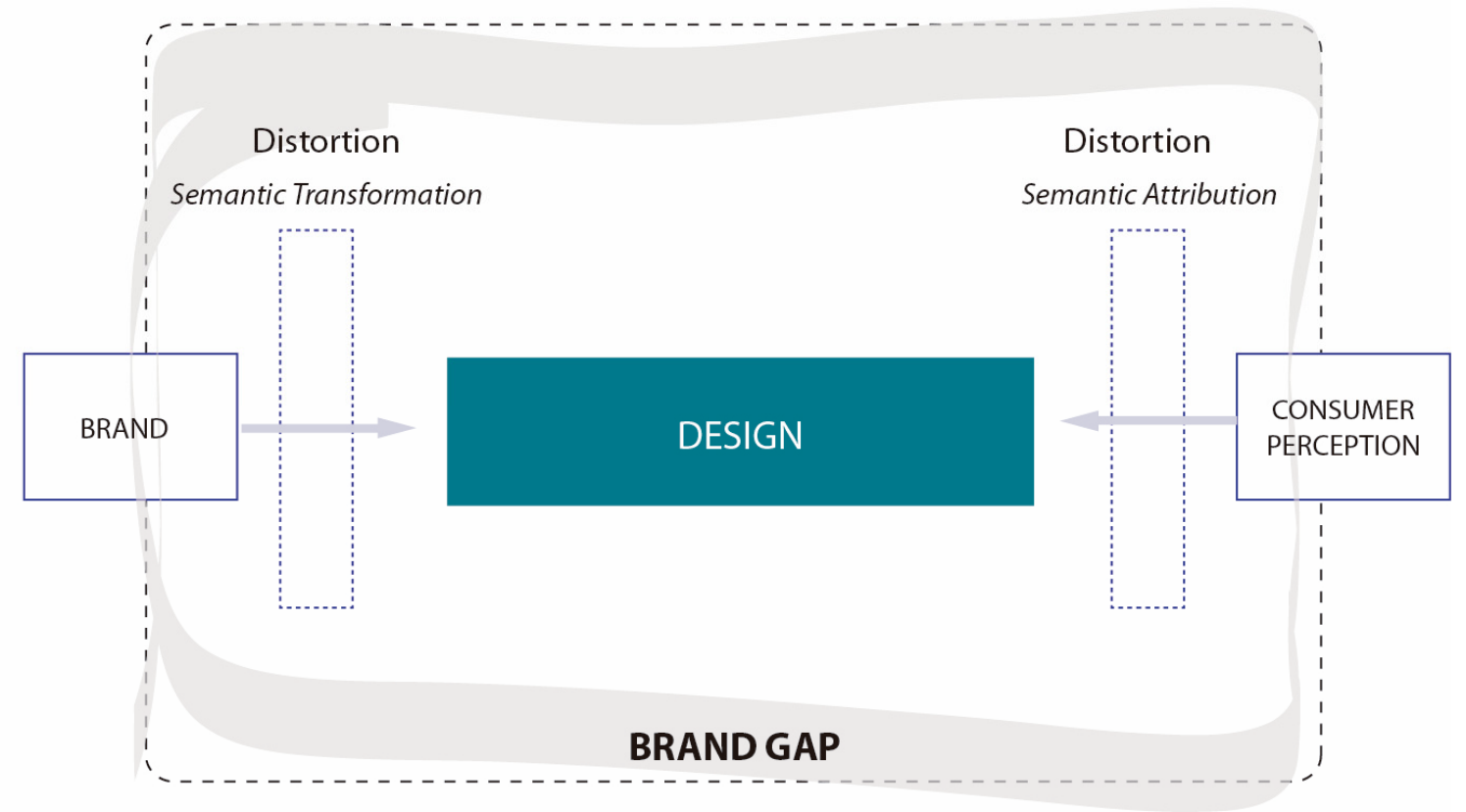

Figure 1. Brand gap interpretation (Gonzalez et al., 2016)

Different authors have created diverse tools and processes to identify aesthetic inconsistencies during the different stages of the design process (Mahajan and Shneiderman, 1997; Warell, 2001; Ozok and Salvendy, 2001; Pugliese and Cagan, 2002; McCormack et al., 2004; Van der Geest and Loorbach, 2005; Karjalainen and Snelders, 2010). However, none of these authors combined static with dynamic product features.

The aim of this paper is to explore how to integrate static aesthetic features like colour and textures with dynamic aesthetic features like gestures and movements.

This exploration is the initial step into further analysing the inconsistencies that might occur when both approaches are taken into consideration. To do so, this paper firstly, introduces a literature review regarding consistency analysis frameworks and aesthetics description. Secondly, it presents an exploratory framework that combines both approaches during some products usage. Finally, an initial laboratory experiment is outline.

\section{Consistency}

The term consistency is inherent to human computer interaction. However, it is also adopted by products to refer to the similarity and familiarity of product's appearance.

Consistency is illustrated by the Cambridge dictionary as "being the same" or as "the quality of always behaving or performing in a similar way, or of always happening in a similar way". Related words include 'coherence', 'familiarity', and 'regularity'. The opposite of consistency is inconsistency. Inconsistency means that irregular patterns emerge when two or more occurrences are compared, between which we would expect regularities. Literature shows that design community has been explored consistency since the $80 \mathrm{~s}$; however, there is still not a commonly agreed definition beyond the conventional meaning.

Consistency in product design has to do with the appearance of the product. Consistency is understood as a degree of product design similarity and familiarity (Hyun et al., 2015) and it is usually related to 
the product aesthetics. Concepts such as design language, visual references or design cues aim to help companies to create a consistent brand environment (Karjalainen, 2003; Karjalainen and Snelders, 2010). This is partly accomplished through the use of certain features throughout the brand's product range.

Consistency in human computer interaction is usually considered in a transfer paradigm in which the higher the similarity between two tasks, the higher the transfer and consistency (Tanaka et al., 1991). Shneiderman (1997) says that the first golden rule of dialog design is strived for consistency. According to Nielsen and Molich (1990) consistency implies that the same action and commands always have the same effect. Consistency is also interpreted as keeping to a particular style or pattern (Gaffney, 2005). Consistency is the user's perception of regularities within a system, leading the user to actions based on previous experiences (Axelsson, 2012).

Despite the existence of a different consistency concept, Reisner (1990) states that consistency is neither a property of the system nor the user, it is the relation between two languages, that of the system, as a designer intended it, and of the competent user. According to Mahajan and Shneiderman (1997) consistency is a relational concept and cannot be defined by itself. A user interface is consistent or inconsistent with respect to something, which may be within the individual application or across a product family.

In this paper aesthetic consistency is understood as the coherent use of static as well as dynamic design features along product usage.

\section{Consistency evaluation methods}

This paper is going to look at tools that analyse consistency, particularly those that consider aesthetics as a relevant aspect. We are going to consider two approaches. Firstly those coming from product design field and secondly those from human machine interaction.

\subsection{Product}

Aesthetic design features are of vital importance due to their potential to create visual consistency and product similarity. Consistency assessment methods and tools try to find how these features have been applied through companies' product design. Some approaches like shape grammar use mathematical rules for consistency while others, like Design Format Analysis rely on qualitative guidelines to understand aesthetic consistency.

The works of Pugliese and Cagan (2002) and McCormack et al. (2004), investigated the use of shape grammars to generate designs for motorcycles and cars that contain brand specific aesthetic features. The shape grammar analyses product geometry using shape, orientation and geometrical variables. Shape grammar evaluation has a quantitative approach where analysis tends to generate a statistical similarity between products and forms.

In a similar manner, Cheutet et al. (2008) improved computer aided tools for modelling aesthetic shapes by studying "aesthetic key lines". Aesthetic key lines were defined as lines on a vehicle surface that were thought of as being aesthetically important. The aim was to preserve the original design intention through the complete vehicle design process. This approach isolated the "aesthetic key lines" from the front side and rear view of vehicles. The isolated lines were then reviewed with respect to the terminology and curve geometry.

Design Format Analysis (DFA) (Warell, 2001) explored the occurrence of selected design features among a variety of products. Features that were deemed as being the most important or relevant for visual recognition were selected from an initial analysis of products approaches. Then, selected products were examined to determine whether or not they incorporated these features.

Karjalainen (Karjalainen, 2003; Karjalainen and Snelders, 2010) used design cues to provide designers with strategic visual references to strengthen the brand's product identity. Other authors (Crilly et al., 2004; Lumar et al., 2014) used design language to refer to a similar concept. Design language is the use of consistent sensory elements in different product offerings that prompts the consumer about their brand identity. Both approaches assume that the familiarity and recognition of the brand can be built using design references (Crilly et al., 2004, 2009; Karjalainen, 2004; Karjalainen et al., 2010). 
All of these studies, although relating to different areas of design, provide examples of aesthetic assessment method and subsequently defined the consistency of a range of products. However, they only take into account those design features coming from the static aesthetic approach.

\subsection{Human machine interaction}

The human machine interaction field focus consistency analysis on the usability and learnability of the Graphic User Interfaces (GUI). They understand aesthetics as a means of reaching better usability and learnability patterns.

Mahajan and Shneiderman (1997) developed a family of consistency checking tools called SHERLOCK. The tool was a software based tool. It was specially focused on textual consistency and it also analysed some visual features centred specifically on button, links and dialog boxes. Mahanan and Shneiderman (1997) understood the aesthetic consistency as similarity in layout and colour use.

Following a similar approach, Sibylle Steinau et al. (2002) focused on aesthetic consistency through colour (background and font) and font size. Despite having a narrow view on aesthetics, the tools asses the inter page consistency in order to analyse the overall web experience.

A broader view of aesthetic consistency was applied by Ozok and Salvendy (2001). They defined consistency as a link between physical, communication and conceptual features of the web site (Kellogg, 1989; Adamson, 1996; Ozok and Salvendy, 2001). They developed the Interface Consistency Testing Questionnaire (ICTQ) (Ozok and Salvendy, 2000, 2001). Out of 94 questions, only 10 questions were about the visual appearance of the text on screen. 6 were about buttons and dialog boxes, and only 1 question was about the visual consistency between various pages on a site (Van der Geest and Loorbach, 2005). Axelsson (2012) introduced user's perspective to Ozok and Salvendy's proposal and they took cognition into consideration defining new consistency categories.

Van der Geest and Loorbach (2005) used a car sorting method to define which aesthetic features users take into account when analysing web site consistency. Among 44 analysed items, colour, background, font, illustration grid/navigation and logo were defined as the most relevant ones.

The approaches coming from human machine interaction applied consistency to graphical user interfaces. Methods tested certain elements of the overall interface, such as dialog boxes, buttons, and background. Among different design features, layout and colour were most commonly used. Most of the tools considered aesthetics as a relevant concept that impact usability and interaction. However, they applied the static aesthetic approach without considering features related to gesture and movement.

\section{Aesthetic design features}

The term aesthetics in the context of this article covers visual and interactive means of effect. Visual aspect are usually covered by static view (Lewalski, 1988) while interactive features are covered by dynamic view (Lenz et al., 2014).

\subsection{Static aesthetic features}

Products can be designed to carry explicit and implicit references (Karjalainen, 2007). Explicit design cues refer to those features that are immediately perceived and recognized. Usually by repeating these features throughout the product portfolio, companies can create similarity and familiarity between products. For example, Volvo defined explicit design cues that include the strong "shoulder" line, the V-shaped bonnet, the characteristic front with the soft nose and diagonal Volvo logo (Karjalainen, 2004).

Implicit cues can be embedded in a variety of different features. This means that repetition of the features might not express the same idea in every product (Crilly et al., 2004). For instance, in the Volvo case, specific shapes were to refer to characteristics, such as safety, dynamism, and Scandinavian design heritage (Karjalainen, 2007). There are potentially a variety of different shapes that can be used to refer to these characteristics and they change in form from one product to the next. These types of features are inherent to a product category. However, if these shapes are repeatedly used in the brand's products, they become explicit cues.

According to Karjalainen (2007) explicit cues are often category-specific, context-sensitive, and subject to product-specific terms of geometry, shape and structure. The transfer of such cues from a product 
category to another is not straightforward. Besides, implicit cues are more easily transferable since they are not inherently connected to a specific product category.

Although the concept of cues does not prioritizes one sense over the other, the application schemes show that usually it makes reference to sight. In addition, some sight items like colour, shape and material / texture are highlighted (Warell, 2001; McCormack et al., 2004; Dell'Era and Verganti, 2007; Ranscombe et al., 2012).

\subsection{Dynamic aesthetic features}

Dynamic features refer to issues related to movements and gestures. For instance, initiating a phone call can be done by pressing or touching a button. The gestures or movements needed to activate a phone call are not a sole matter of efficiency. In fact, many new interaction techniques may be even less efficient (Lenz et al., 2017). When interaction goes beyond efficiency, it becomes a matter of identity, innovation and differentiation.

Interaction approach proposes that interaction qualities can be described at two different levels: motor level and be level.

Motor level qualities take place on motor action (operations) such as turning a knob and pressing a lever. Psychological action theories point out that motor actions are highly automatized and often performed unconsciously (Diefenbach et al., 2013). This is a barrier to conscious thinking about interaction in terms of its basic qualities (e.g., powerful, slow). Consequently, only a limited number of approaches focus on the aesthetics of interaction at this level (Lenz et al., 2017). These actions mostly focus on a specific technology or domain such as graphical user interfaces (Lim et al., 2007), gestural interfaces (Saffer, 2009) or movement based interaction (Ross and Wensveen, 2010).

Be level features focus on describing emotions, experiences, perceptions of interaction and personal sensations (Petersen et al., 2004; Löwgren, 2009). They define the reasons which make the interaction meaningful to people (Diefenbach et al., 2013; Lenz et al., 2017). Be level interactions are dependent on motor ones.

Different authors describe different items when referring to aesthetics interaction. However, the most predominant one is the spatial features. It describes the paths of the movements and the gestures. Another two interesting item are the time invested in the movement and the forces needed to activate the products (Lenz et al., 2014, 2017; Hur et al., 2017).

\section{Aesthetic consistency framework}

A basic framework for aesthetics as a process of communication is going to be the foundation to integrate and combine static and dynamic design features. This foundation will be further developed to analysed consistency.

\subsection{Foundation for aesthetic interaction consistency framework}

Shannon (1949) described a basic system of communication based on five elements: source, transmitter, channel, receiver and destination. The information source generates a message which is encoded into a signal and transmitted across a channel. The receiver decodes the signal and the message arrives at the destination.

Monö (1997) applied Shannon's model to the study of product design. The producer is in charge of designing and manufacturing the product. The designer is considered as the source of the message. The product is viewed as the transmitter of the message and the environment in which the consumer interacts with the product is regarded as the channel. The consumer is involved in both, the perception of the product and the following response. Consequently, the consumer's perceptual senses may be regarded as the receiver of the design message and their faculty for response may be regarded as the destination. The traditional view of consumer behaviour presents response to products as encompassing cognition and affect which are followed by behaviour (Bloch, 1995; Crilly et al., 2004).

Crilly et al. (2004) considers that consumers act on both the artefact and their environment, both of which respond in a way that provides feedback to the senses (Figure 2). 


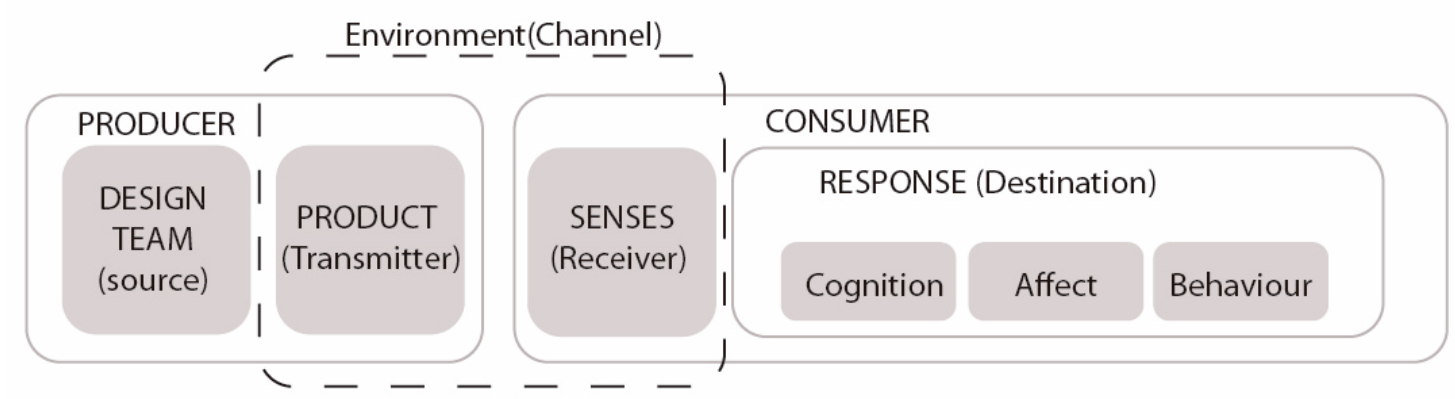

Figure 2. Framework for design as a process of communication (Crilly et al., 2004)

We focus on how aesthetic features are treated during this process. The company defines certain aesthetic features that might represent the brand identity, product category and product usability. These features are implemented by designer through certain rules and design guidelines, resulting in a product. When the product is presented to the consumer, they receive these features through their senses, they interpret them and, as a consequence users act on the product.

The framework (Figure 3) considers that, when a product is presented to the user, they will perceive design features through all the senses (product presentation) (Crilly et al., 2004; Karjalainen, 2010). Based on what the user perceives, they will interact with the product using gestures or body movements (user action) (Lenz et al., 2014). The consumer's action might create a product reaction (Product reaction) (Crilly et al., 2004, 2009). The product's reaction might be a sound, an aesthetic change or a product movement. If the reaction brings a significant change to the product aesthetics, then the user will face a new product presentation. So, again this new presentation will be perceived by the user's senses and as a consequence a new action and reaction will happen.

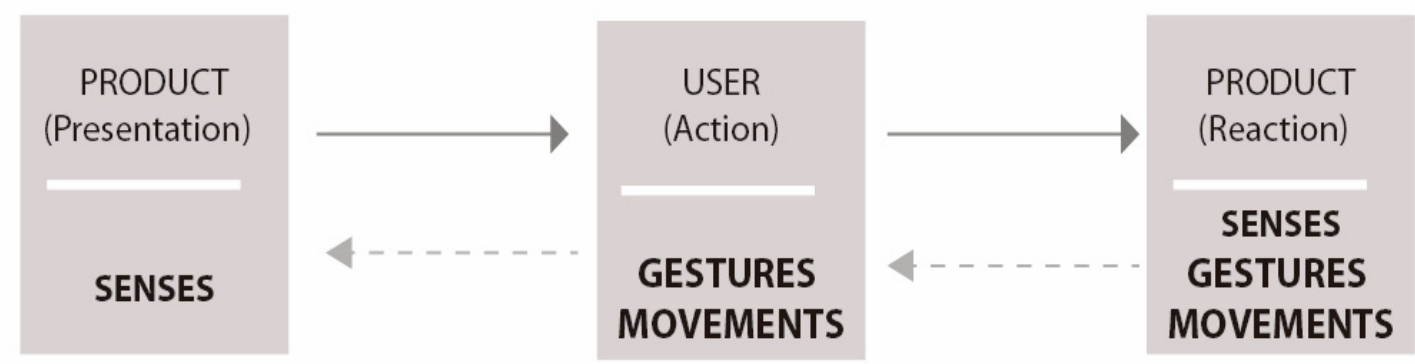

Figure 3. Aesthetic consistency framework

During this process a vast amount of variables might create aesthetic inconsistencies. The frameworks analyse the aesthetic features along the product usage and aims to identify potential aesthetic inconsistencies that might impact in the product usability, learnability and brand trust ability.

\subsection{Design features for aesthetic consistency framework}

Information about design features applied to the products need to be collected based on the aesthetic consistency framework showed is based on Figure 2. The data collection will be divided into 3 stages (Table 1): Presentation, action and reaction.

Presentation stage aims to list all the features related to static product descriptions. It is about those aspects that can be perceived by user's senses (more detailed features are described in Section 5.1) with special attention given to sight. For instance, colour, material or shape related features could be part of the presentation stage.

The aim of the action stage is to collect features related to dynamic product description. These features are body movements and gestures (Lenz et al., 2014) (more detailed features are described in Section 5.2).The idea behind action is to collect all these movements that the users need to do in order to reach 
their goals. For instance, to open a water bottle the user could pull the hook cover upwards, push a button or just unscrew the cap.

The reaction stage aims to gather product responses. Product response is related to how the product behaves when the user makes a gesture or movement. Based on the theory of action-reaction, when the user makes a gesture, for instance pushing a button, the product response. If the same action has different reactions then the user might get confused. This confusion is caused because of the existence of aesthetic inconsistency.

Table 1. The three stages of aesthetic interaction consistency framework

\begin{tabular}{|l|l|}
\hline PRESENTATION & $\begin{array}{l}\text { Static features } \\
\text { e.g. colour, texture, hue, audio. }\end{array}$ \\
\hline ACTION & $\begin{array}{l}\text { Dynamic features } \\
\text { e.g. push, pull, slide. }\end{array}$ \\
\hline REACTION & $\begin{array}{l}\text { Static and dynamic features } \\
\text { Change of colour, movement, change of shape. }\end{array}$ \\
\hline
\end{tabular}

As Karjalainen (2010) explains, some characteristics are specific to the product that we are analysing. These specific features can be used to compare products from the same product category. However, they might not be suitable to compare, such as a simple product like a bottle with a complex product like a car or a physical product with a digital one. In these cases, more abstract and perceptual features should be used. These abstract features are related to explicit design cues.

Lenz et al. $(2014,2017)$ also agrees that aesthetics needs to be described from an operational to more experiential and perceptual level. Motor level features describe the operational aspect of the movement through specific design issues like pushing or turning. Be level features describe more experiential and perceptual features of the movement and it might be used more abstract features like soft or mechanical. Consequently, the combination of both specific and abstract features might be needed. Specific features are related and are specific to that product. They are also more objective and they are usually focused on one item like colour, hue, or curve shape. On the other hand, abstract features are related to more perceptual aspects like hot or aggressive colour. In addition, they might combine more than one item. For instance, the term minimalistic might refer to a shape, colour, structure, and so on. Finally, they are easily transferable to most of the product categories.

So, both abstract and specific features are needed to understand product aesthetic consistency. White colour does not mean that a product is minimalistic and vice versa, yet they are complementary and help designers to visualize better how the product should looks in order to find inconsistencies.

\section{Method}

The framework above-mentioned is applied to a specific context with a specific procedure and participants.

\subsection{Context}

The application context showed in Figure 4 describes the usage of three different elevator's destination panel. The usage sequence is "to select the destination floor when you are in an elevator" and it is the same in the three systems.

The experiment is done in a laboratory with 4 senior designers. Since the designers cannot travel in the real elevator, some videos are recorded and some pictures are taken. The recorded videos simulate a real journey in the elevator. Overall, 3 sequences are analysed, each of them in a different elevator (Figure 4).

The designers need to describe the design features of the presentation, action, and reaction of the sequences. For that purpose, they will use both specific and abstract features. Analysing the sequences throughout all the senses and gestures is a complex and time consuming task. Consequently, designers are advised to focus on some specific details in each stage. The column "proposed items" of the Figure 4 shows the details. 


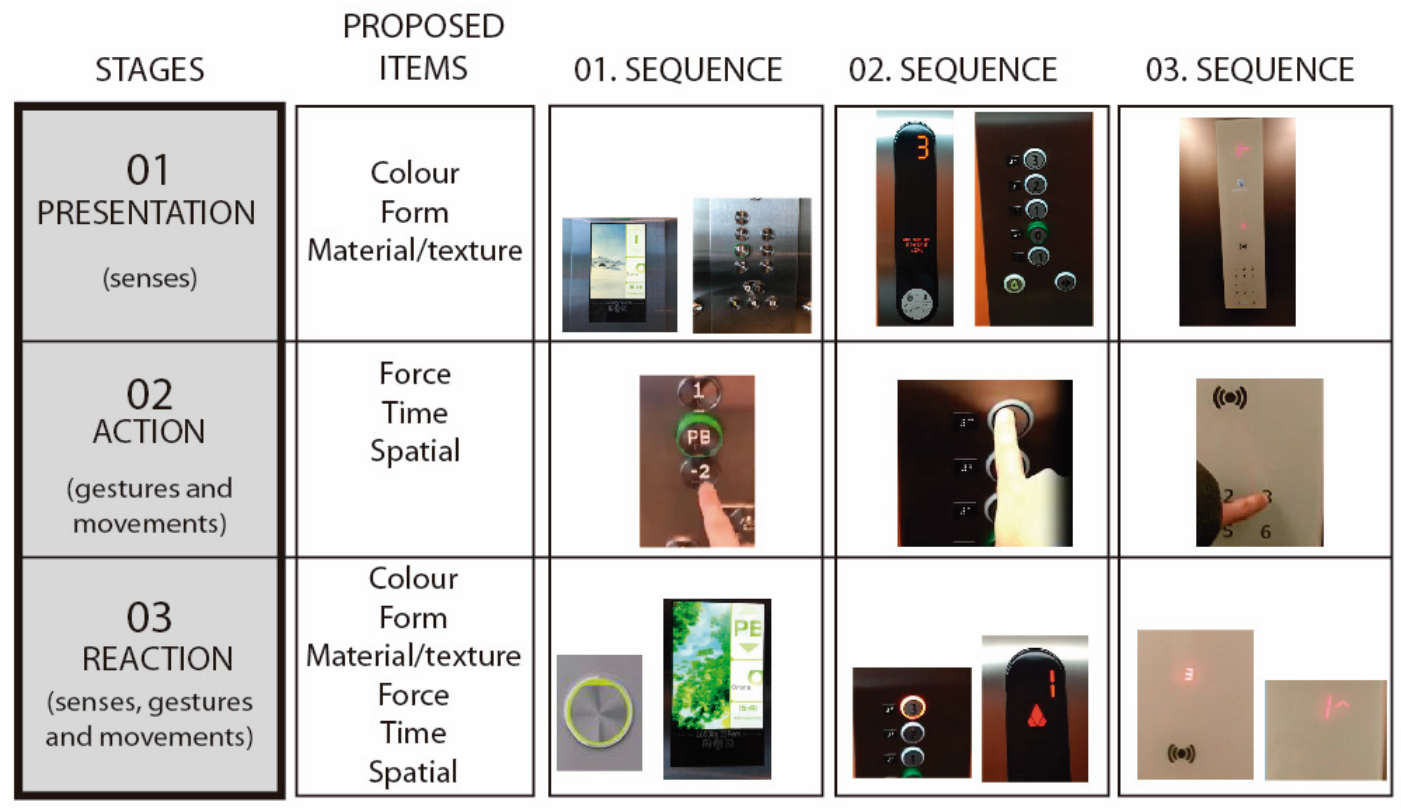

Figure 4. Application context

In the presentation stage users need to focus on the sight sense. In addition they are encouraged to describe those sight items related to colour, form and material/ texture. In the action stage, the movement and the gestures need to be described base on the next 3 item. The force to be used in the movement, the time needed for the movement and the space or spatial path that the movement takes. Finally, to describe the reaction stage, the 6 item are considered: colour, form, texture /material and force, temporal and spatial features.

\subsection{The procedure}

Firstly, designers need to describe the elevator with which they will interact (presentation). Next, they will define the interaction patterns to select the destination floor number (action). Finally, they will analyse how the product responds (response).

The process is divided into 4 phase: In the first phase (1), the project goal and the experiment main ideas are explained to the designers. In addition, some videos are shown and the material needs for the development of the experiment is distributed, such as pictures of the sequences and templates to list the features. In the second phase (2), designers explore the design features individually. Each designer has 15 minutes per sequence to analyse the design features. In the third phase (3), designers share their features and their thoughts during 90 minutes. In the last phase (4), designers discuss about the obtained results and followed process. This last phase takes around 30 minutes.

\section{Results}

This exercise has resulted in a large initial list of aesthetic features. From this initial list, repeated features and synonyms or familiar features were deleted. The Figure 5 shows a sample of those features. The design features describe both, the general features of the product such as metallic or long and features that are related to a specific part of the product, such as round button and green light ring. So, the depth and the level of detail that features can cover vary.

The aesthetic features coming from both static and dynamic perspectives create a much more detailed description about the product. In addition, they can be easily combined in the same framework. However, designers invested much more time describing the presentation stage than the action or reaction stage. So, a lot more static aesthetic features have been gathered. 


\begin{tabular}{|c|c|c|c|c|c|c|}
\hline \multirow[b]{3}{*}{ 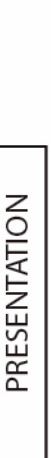 } & \multicolumn{2}{|c|}{ 01. SEQUENCE } & \multicolumn{2}{|c|}{ 02. SEQUENCE } & \multicolumn{2}{|c|}{ 03. SEQUENCE } \\
\hline & SPECIFIC & ABSTRACT & SPECIFIC & ABSTRACT & SPECIFIC & ABSTRACT \\
\hline & $\begin{array}{l}\text { Metallic } \\
\text { Long and square } \\
\text { Button:Metallic grey } \\
\text { Black numbers } \\
\text { Button long layot } \\
\text { Circular buttons } \\
\text { Square display } \\
\text { White background display } \\
\text { Black frame display } \\
\text { White with green details }\end{array}$ & $\begin{array}{l}\text { Cold } \\
\text { Cleansed } \\
\text { Organized } \\
\text { Industrial }\end{array}$ & $\begin{array}{l}\text { Metalic } \\
\text { Long and square } \\
\text { Button: Metallic grey } \\
\text { White numbers } \\
\text { Button long layot } \\
\text { Circular buttons } \\
\text { Long display } \\
\text { Black backround display } \\
\text { Display detaild in orange }\end{array}$ & $\begin{array}{l}\text { Chubby and } \\
\text { playful shape } \\
\text { Screen } \\
\text { serious color }\end{array}$ & $\begin{array}{l}\text { White glaze } \\
\text { Long and square } \\
\text { Button embeded } \\
\text { Black big numbers } \\
\text { Button phone style layot } \\
\text { Smoth rounded corners }\end{array}$ & $\begin{array}{l}\text { Minimalistic } \\
\text { Clean } \\
\text { Fragile } \\
\text { Moderm }\end{array}$ \\
\hline$\stackrel{z}{\text { 은 }}$ & $\begin{array}{l}\text { Push in } 3 \mathrm{~mm} \\
\text { Push slightly with a finger } \\
\text { Straight path } \\
\text { Horizontal path }\end{array}$ & $\begin{array}{l}\text { Old fachion } \\
\text { Mechanical } \\
\text { Smooth }\end{array}$ & $\begin{array}{l}\text { Push in } 3 \mathrm{~mm} \\
\text { Push slightly with a finger } \\
\text { Straight path } \\
\text { Horizontal path }\end{array}$ & $\begin{array}{l}\text { Old fachion } \\
\text { Mechanical }\end{array}$ & $\begin{array}{l}\text { Touch } \\
\text { Touch slightly with a finger }\end{array}$ & Simple \\
\hline 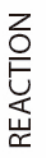 & $\begin{array}{l}\text { Button green light ring } \\
\text { Floor change } \\
\text { Arrow breathing } \\
\text { Number blinking }\end{array}$ & $\begin{array}{l}\text { Smoth } \\
\text { breathing } \\
\text { Mechanical } \\
\text { blink } \\
\text { Closed arrow }\end{array}$ & $\begin{array}{l}\text { Button orange light ring } \\
\text { Floor change } \\
\text { Number blinking }\end{array}$ & $\begin{array}{l}\text { Mechanical } \\
\text { blink } \\
\text { Vintage arrow }\end{array}$ & $\begin{array}{l}\text { Redish numbres and arrows } \\
\text { Floor change } \\
\quad \text { Number blinking } \\
\text { Two lines arrow }\end{array}$ & $\begin{array}{l}\text { Mechanical / } \\
\text { fast blink }\end{array}$ \\
\hline
\end{tabular}

Figure 5. Aesthetic interaction design features from the 3 sequences

Observing the presentation stage of different sequences, we see that long and square specific feature is repeated. Feature repetition is a sign of consistency. However, paying attention to the abstract features, we observe that there is not similarity or familiarity among sequences. This means that the long and square feature is an inherent product category feature instead of a sign of interaction aesthetic consistency. Hence, design features could be determined by the product category or by the brand identity. So, when analysing aesthetic interaction consistency we should be able to differentiate features coming from product category and those coming from brand or product identity.

The results show several potential inconsistencies. For instance, in the first sequence, while the graphical interface shows square structure, the flor buttons show a rounded shape. Or that the typography to communicate the floor 1 is not the same in the button and in the screen. In the second sequence for instance the bottom are rounded and creepy and the arrow displayed has a vintage style.

The process was followed without any complication. Designers were able to describe properly the presentation, action and reaction stages. In addition, both levels, specific and abstract, were filled without any difficulty. Thus, the framework seams easy to understand and easy to apply for experimented designers.

Finally, the frame offers huge opportunities as an initial phase of aesthetic interaction consistency tool. Since consistency is about comparing, we have analysed how comparable are all these features between sequences. The results show that unless some difficulties it is easy to apply and combine.

\section{Conclusion}

Despite the awareness of aesthetic features as a strategic asset capable of creating identity and brand consistency, aesthetics still remains in its traditional and static view. Even though more modern approaches show the values of interaction aspect, its application and comprehension is still in its infancy. The framework is a further step towards the comprehension of aesthetic interaction that integrates static features as well as dynamic features.

The proposed framework brings together two domains of aesthetic which usually are addressed separately when it comes to analyse aesthetics and aesthetic consistency. The frame integrates both in an easy and comprehensible manner.

The frame can be used to analyse any type of products and sequences, from more simple products to more complex ones. It even might be used to analyse physical product as well as digital and web base 
application. The combination of specific and abstract design aspects will allow comparing and analysing products from different categories and forms.

The framework seems interesting to analyse consistency within the different sequences from the same product as well as among different products at the same sequence.

As we already have mentioned dynamic elements are not always considered in the product design processes, so inconsistencies might appear. For instance, in the first sequence when the floor change, the number blinks while the arrow breaths. In the second sequence while the general product form is playful, the arrow of the reaction is considered vintage. These examples might be regards as potential inconsistencies.

We consider that the frame could analyse a more extended interaction sequences to examine products aesthetic interaction consistency. This approach might have potential in those products that are interaction intensive like web application or intelligent products.

The potential inconsistencies are considered equally relevant. The framework does not demonstrate how each inconsistency affects users and alter the user behaviour. We consider that to group the inconsistencies and to define a severity ranking might help to take more efficient design strategies.

Base on the heuristic evaluation recommendation (Nielsen and Molich, 1990) the sequence was evaluated by 4 senior designer. Heuristic technique requires three or more expects to identify usability problems in a timely manner with reasonable cost. However, there is a lack of sufficient studies that corroborate whether those heuristic patterns can be applied to identify the major aesthetic consistency problems of a product usage.

\section{Limitations and future research}

The framework in this paper has limitations, both in terms of product category and sequence extension. The types of product, the limited propose item and the sequence extension dampened the results. Future research need to extend all these factors to better describe the extent to which the framework contributes to aesthetic consistency analysis.

The study is based on qualitative exploratory research. Thus the external validity (generalizability) of the findings cannot be assessed. Future research could improve our findings through insights from additional case studies.

Furthermore, the results are context dependent since the model was tested in the research project context. This should, therefore, be considered as initial evaluation of the tool, requiring further case studies development and verification.

Since the test was control in the laboratory, the usability aspects related to the inconsistent use of aesthetic interaction features have not been considered.

\section{References}

Adamson, P.J. (1996), A comparison between consistent and inconsistent graphical user interfaces, PhD thesis, University of North Florida.

Axelsson, A. (2012), Consistency in Web Design from a User Perspective, Bachelor thesis.

Bloch, P.H. (1995), "Seeking the Ideal Form: Product Design and Consumer Response", Journal of Marketing, Vol. 5 No. 3, pp. 16-29. https://doi.org/10.2307/1252116

Cheutet, V., Léon, J.C., Catalano, C.E., Giannini, F., Monti, M. and Falcidieno, B. (2008), "Preserving car stylists' design intent through an ontology", International Journal on Interactive Design and Manufacturing, Vol. 2 No. 1, pp. 9-16. https://doi.org/10.1007/s12008-007-0031-3

Crilly, N., Moultrie, J. and Clarkson, P.J. (2004), "Seeing things: consumer response to the visual domain in product design", Design studies, Vol. 25 No. 6, pp. 547-577. https://doi.org/10.1016/j.destud.2004.03.001

Crilly, N., Moultrie, J. and Clarkson, P.J. (2009), "Shaping things: intended consumer response and the other determinants of product form", Design Studies, Vol. 30 No. 3, pp. 224-254. https://doi.org/10.1016/j.destud.2008.08.001

Dell'Era, C. and Verganti, R. (2007), "Strategies of innovation and imitation of product languages", Journal of Product Innovation Management, Vol. 24 No. 6, pp. 580-599. https://doi.org/10.1111/j.15405885.2007.00273.x

Diefenbach, S., Lenz, E. and Hassenzahl, M. (2013), "An interaction vocabulary. describing the how of interaction", CHI'13 Extended Abstracts on Human Factors in Computing Systems (CHI EA '13), Paris, 
France, April 27 - May 2, 2013, ACM, New York, USA, pp. 607-612. https://doi.org/10.1145/2468356.2468463

Gaffney, G. (2005), Why Consistency is Critical. [online] Available at: https://www.sitepoint.com/whyconsistency-is-critical/

Gonzalez, I., Val, E., Justel, D. and Iriarte, I. (2016), "Closing the brand gap through innovation and design", Procedia CIRP, Vol. 50, pp. 112-116. https://doi.org/10.1016/j.procir.2016.05.100

Gonzalez, I., Val, E., Justel, D. and Iriarte, I. (2017), “A Framework For Product Design Based On Semantic Attribution Process", The Design Journal, Vol. 20, pp. S16-S27. https://doi.org/10.1080/14606925.2017.1352983

Hur, Y., Sturdee, M., Alonso, M.B., Markopoulos, P. and Alexander, J. (2017), "Fiction and Physicality: a designerly approach towards complexities of emerging technologies", The Design Journal, Vol. 20, pp. S3849S3862. https://doi.org/10.1080/14606925.2017.1352888

Hyun, K.H., Lee, J.H., Kim, M. and Cho, S. (2015), "Style synthesis and analysis of car designs for style quantification based on product appearance similarities", Advanced Engineering Informatics, Vol. 29 No. 3 , pp. 483-494. https://doi.org/10.1016/j.aei.2015.04.001

Karjalainen, T.M. (2003), "Strategic brand identity and symbolic design cues", Proceedings of the 6th Asian Design Conference (6th ADC), Tsukuba, Japan, October 14-17, 2003, pp. 1-13.

Karjalainen, T.M. (2004), Semantic Transformation in Design, University of Art and Design, Helsinki.

Karjalainen, T.M. (2007), "It looks like a Toyota: Educational approaches to designing for visual brand recognition", International Journal of Design, Vol. 1 No. 1, pp. 67-81.

Karjalainen, T.M. and Snelders, D. (2010), "Designing visual recognition for the brand", Journal of Product Innovation Management, Vol. 27 No. 1, pp. 6-22. https://doi.org/10.1111/j.1540-5885.2009.00696.x

Kellogg, W.A. (1989), “The dimensions of consistency”, In: Nielsen, J. (Ed.), Coordinating user interfaces for consistency, Academic Press Professional, San Diego, CA, pp. 9-20.

Lenz, E., Diefenbach, S. and Hassenzahl, M. (2014), "Aesthetics of interaction: a literature synthesis", Proceedings of the 8th Nordic Conference on Human-Computer Interaction: Fun, Fast, Foundational (NordiCHI '14), Helsinki, Finland, October 26-30, 2014, ACM, New York, pp. 628-637. https://doi.org/10.1145/2639189.2639198

Lenz, E., Hassenzahl, M. and Diefenbach, S. (2017), “Aesthetic interaction as fit between interaction attributes and experiential qualities", New Ideas in Psychology, Vol. 47, pp. 80-90. https://doi.org/10.1016/j.newideapsych.2017.03.010

Lewalski, Z.M. (1988), Product Esthetics: An Interpretation for Designers, Design and Development Engineering Press, Carlson City, Nevada.

Lim, Y.K., Stolterman, E., Jung, H. and Donaldson, J. (2007), "Interaction gestalt and the design of aesthetic interactions", Proceedings of the 2007 conference on Designing pleasurable products and interfaces (DPPI '07), Helsinki, Finland, August 22-25, 2007, ACM, New York, pp. 239-254. https://doi.org/10.1145/1314161.1314183

Löwgren, J. (2009), "Toward an articulation of interaction aesthetics", New Review of Hypermedia and Multimedia, Vol. 15 No. 2, pp. 129-146. https://doi.org/10.1080/13614560903117822

Mahajan, R. and Shneiderman, B. (1997), "Visual and textual consistency checking tools for graphical user interfaces", IEEE Transactions on Software Engineering, Vol. 23 No. 11, pp. 722-735. https://doi.org/10.1109/32.637386

McCormack, J.P., Cagan, J. and Vogel, C.M. (2004), "Speaking the Buick language: capturing, understanding, and exploring brand identity with shape grammars", Design studies, Vol. 25 No. 1, pp. 1-29. https://doi.org/10.1016/S0142-694X(03)00023-1

Monö, R. (1997), Design for product understanding: The aesthetics of design from a semiotic approach, Liber.

Neumeier, M. (2003), The Brand Gap: How to Bridge the Distance Between Business Strategy and Design, New Riders, Indianapolis.

Newbery, P. and Farnham, K. (2013), Experience design: a framework for integrating brand, experience and value, John Wiley \& Sons, New Jersey.

Nielsen, J. and Molich, R. (1990), "Heuristic evaluation of user interfaces", Proceedings of the SIGCHI conference on Human factors in computing systems (CHI '90), Seattle, Washington, April 1-5, 1990, ACM, New York, pp. 249-256. https://doi.org/10.1145/97243.97281

Ozok, A.A. and Salvendy, G. (2000), "Measuring consistency of web page design and its effects on performance and satisfaction", Ergonomics, Vol. 43 No. 4, pp. 443-460. https://doi.org/10.1080/001401300184332

Ozok, A.A. and Salvendy, G. (2001), "How consistent is your web design?", Behaviour \& Information Technology, Vol. 20 No. 6, pp. 433-447. https://doi.org/10.1080/01449290110092260

Petersen, M., Iversen, O., Krogh, P.G. and Ludvigsen, M. (2004), “Aesthetic Interaction: a pragmatist's aesthetics of interactive systems", Proceedings of the 5th conference on Designing interactive systems: processes, 
practices, methods, and techniques (DIS '04), Cambridge, USA, August 1-4, 2004, ACM, New York, pp. 269276. https://doi.org/10.1145/1013115.1013153

Pugliese, M.J. and Cagan, J. (2002), "Capturing a rebel: modeling the Harley-Davidson brand through a motorcycle shape grammar", Research in Engineering Design, Vol. 13 No. 3, pp. 139-156. https://doi.org/10.1007/s00163-002-0013-1

Ranscombe, C., Hicks, B. and Mullineux, G. (2012), “A method for exploring similarities and visual references to brand in the appearance of mature mass-market products", Design Studies, Vol. 33 No. 5, pp. 496-520. https://doi.org/10.1016/j.destud.2012.04.001

Reisner, P. (1990), "What is consistency?", Proceedings of IFIP TC 13 Third International Conference on HumanComputer Interaction (INTERACT '90), Cambridge, UK, August 27-31, 1990, North-Holland, Amsterdam, pp. 175-181.

Ross, P.R. and Wensveen, S.A. (2010), "Designing behavior in interaction: Using aesthetic experience as a mechanism for design", International Journal of Design, Vol. 4 No. 2.

Saffer, D. (2009), Designing Gestural Interfaces, O’Reilly Media, Sebastopol.

Schwarzfischer, K. (2011), "The Aesthetic Meaning of Syntactic, Semantic and Pragmatic Gestalt Integrations in Integrative Aesthetics", Gestalt Theory, Vol. 33 No. 3-4, pp. 345-362.

Shannon, C.E. (1949), "Communication theory of secrecy systems”, Bell Labs Technical Journal, Vol. 28 No. 4, pp. 656-715. https://doi.org/10.1002/j.1538-7305.1949.tb00928.x

Shneiderman, B. (1997), Designing the user interface: Strategies for effective human-computer interaction, 3rd ed., Addison-Wesley, Boston.

Steinau, S., Díaz, O., Rodríguez, J.J. and Ibáñez, F. (2002), “A Tool for Assessing the Consistency of Websites", Proceedings of the 4th International Conference on Enterprise Information Systems (ICEIS'02), Ciudad Real, Spain, April 3-6, 2002, Kluwer Academic Publishers, Hingham, pp. 227-234.

Tanaka, T., Eberts, R.E. and Salvendy, G. (1991), "Consistency of human-computer interface design: quantification and validation", Human Factors, Vol. 33 No. 6, pp. 653-676. https://doi.org/10.1177/001872089103300604

Van der Geest, T. and Loorbach, N. (2005), "Testing the visual consistency of web sites", Technical communication, Vol. 52 No. 1, pp. 27-36.

Warell, A. (2001), Design syntactics: a functional approach to visual product form theory, models, and methods, $\mathrm{PhD}$ thesis, Chalmers University of Technology.

Itsaso Gonzalez, Researcher/Lecturer

Design Innovation Center (DBZ), Mondragon Unibertsitatea, Mechanical and Manufacturing

Mondragon Goi Eskola Politeknikoa J.m.a. S.Coop., 20500 Mondragon, Spain

Email: igonzalez@mondragon.edu 